\section{El grosor macular podría ser un predictor de la probabilidad de recidiva de los edemas maculares por oclusiones venosas de la retina tratados mediante inyecciones intravítreas repetidas de antiangiogénicos}

Macular thickness might be a recurrence probability predictor in macular edema due to retinal vein occlusions treated with repeated intravitreal injections of antiangiogenics

\section{Sr. Director:}

La patología venosa oclusiva de la retina constituye junto con la retinopatía diabética, la causa principal de alteraciones de la visión central en sujetos menores de 50 años (1). En ambas entidades el principal factor implicado en la pérdida visual es el edema macular (2).

A lo largo de los últimos años las diversas opciones terapéuticas disponibles a la hora de abordar el edema macular asociado a oclusiones venosas retinianas se podrían resumir en la fotocoagulación retiniana, el uso de corticoides intravítreos o subtenonianos o la cirugía vitreorretiniana. No obstante, con la entrada en el mercado de los fármacos intravítreos antiangiogénicos (Pegaptanib y Ranibizumab) los algoritmos terapéuticos previos han experimentado notables modificaciones. Se ha asociado al Factor de Crecimiento Vascular Endotelial (VEGF) como determinante en la patogenia del

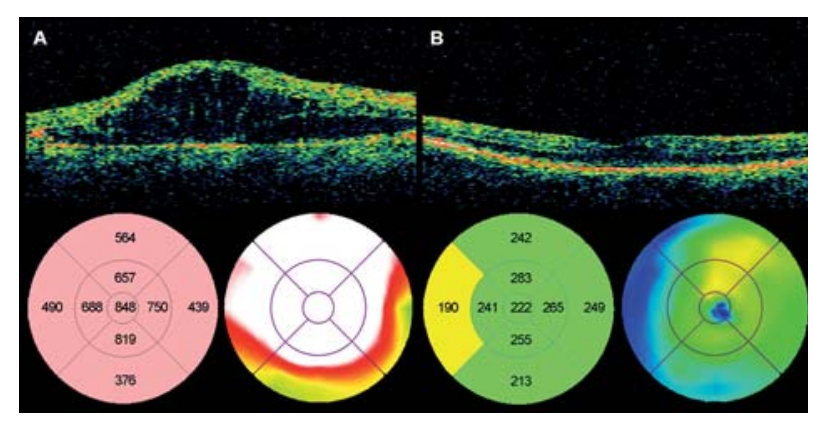

Fig. 1: Paciente con oclusión de rama venosa temporal superior en su ojo derecho (A). Tras dos tratamientos intravítreos presenta perfil foveal normalizado, con grosores en el mapa retiniano de 300 micras (B), mateniéndolo así a lo largo de las 8 semanas siguientes sin inyecciones adicionales.

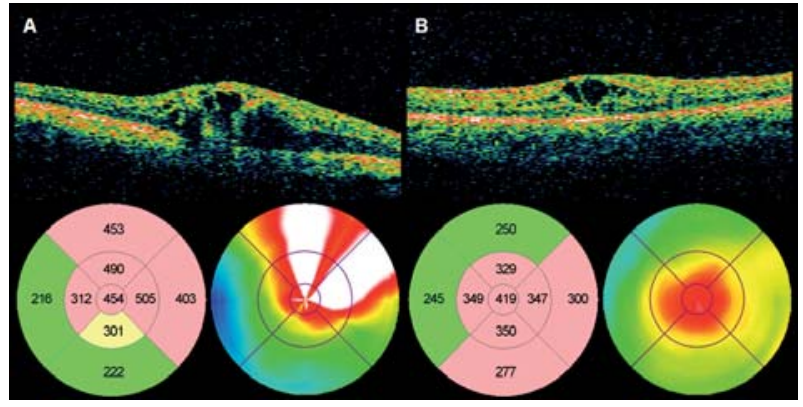

Fig. 2: Paciente con oclusión de rama venosa temporal superior en su ojo izquierdo (A). Tras dos tratamientos intravítreos presenta perfil foveal normalizado, con grosores en el mapa retiniano superiores a 300 micras. La recidiva se produce a los 15 días de no retratar $(B)$.

edema de la mácula en pacientes con oclusiones venosas retinianas (3) y, por lo tanto, su inhibición pasa por ser crucial en el abordaje terapéutico.

En nuestro caso, los edemas maculares asociados a oclusiones de rama venosa de la retina son tratados con inyecciones de antiangiogénicos en número dependiente de la reducción en el grosor macular estimado por OCT. Contamos con una serie de 17 pacientes (15 oclusiones de rama temporal superior y dos oclusiones de vena central) tratados de este modo desde enero del año 2007 hasta agosto del año 2008. Hemos percibido que en aquellos sujetos en los que conseguimos reducir el grosor macular por debajo de 300 micras en todo el mapa retiniano calculado por OCT (protocolo de análisis retinal thickness map) desaparecen las recidivas del edema. Esta circunstancia se ha dado en cuatro de los 17 pacientes y en todos ellos no han sido necesarios los retratamientos y los resultados visuales son excelentes; el grosor macular medio en esos sujetos fue de 244,75 micras tras 2,75 tratamientos intravítreos (con grosor medio inicial de 493 micras) con una visión final media de 0,625 (visión inicial media de 0,24 ). Los cuatro sujetos presentaron una oclusión de rama venosa temporal superior. El seguimiento de esos pacientes ha sido de 8,5 semanas de media que, aunque ciertamente es un periodo corto, contrasta con la precocidad con la que la OCT detecta la recidiva del edema en los 13 casos restantes; en todos ellos la revisión programada después de cuatro semanas recoge grosores maculares por encima de las 300 micras y cuando no se tratan en ese momento la siguiente revisión a las cuatro semanas (ocho semanas tras el último tratamiento intravítreo) refleja grosores maculares constante- 
mente superiores a los de la visita previa. La probabilidad de recidiva se ha mostrado independiente del grosor macular basal al inicio.

Confiando en que los ensayos multicéntricos y los numerosos estudios puestos en marcha en todo el mundo puedan ayudarnos a planificar una estrategia que optimice los resultados de los tratamientos para el edema macular asociado a oclusión venosa retiniana, planteamos la diana terapéutica en estos pacientes en conseguir un grosor macular por debajo de 300 micras, puesto que parece que de este modo desaparece la recidiva del mismo y se obtienen resultados visuales definitivos.

Gallego-Pinazo $\mathrm{R}^{1}$, Díaz-Llopis $\mathrm{M}^{2,3}$, Francés $\mathrm{E}^{2}$, López-Lizcano $\mathrm{R}^{4}$, Gómez-Maestra $\mathrm{M}^{4}$, Udaondo $\mathrm{P}^{1}$

${ }^{1}$ Licenciado en Medicina. Especialista en Oftalmología. ${ }^{2}$ Doctor en Oftalmología.
3 Universidad de Valencia. Facultad de Medicina. ${ }^{4}$ Licenciado en Medicina. Residente de Oftalmología Hospital Universitario La Fe de Valencia. Servicio de Oftalmología. Unidad de Mácula E-mail: robertogallego@comv.es

\section{BIBLIOGRAFÍA}

1. Fuller JJ, Masson JO. Retinal vein occlusions: update and therapeutic advances. In: American Academy of Ophthalmology. Focal Points, Clinical Modules for Ophthalmology. San Francisco: American Academy of Ophthalmology. 2007.

2. Schachat AP. A new look an old treatment for diabetic macular edema. Ophthalmology 2008; 115: 1445-1446.

3. Campochiaro PA, Hafiz G, Shah SM, Nguyen QD, Ying H, Do DV, et al. Ranibizumab for macular edema due to retinal vein occlusions: implication of VEGF as a critical stimulator. Mol Ther 2008; 16: 791-799. 